Table 1. Baseline characteristics

\begin{tabular}{|c|c|c|c|}
\hline \multirow{2}{*}{ Age, years } & UPA & UPA + MTX & Total \\
\hline & $\begin{array}{c}57.7(13.2) \\
n=257\end{array}$ & $\begin{array}{c}58.1(11.4) \\
n=276\end{array}$ & $\begin{array}{c}57.9(12.3) \\
n=533\end{array}$ \\
\hline \multirow{2}{*}{ Disease duration, years } & $9.4(8.3)$ & $8.5(7.7)$ & $9.0(8.0)$ \\
\hline & $n=253$ & $\mathrm{n}=272$ & $n=525$ \\
\hline CRP, mg/dL & $\begin{array}{c}1.3(1.9) \\
n=257\end{array}$ & $\begin{array}{c}1.1(1.7) \\
\mathrm{n}=276\end{array}$ & $\begin{array}{c}1.2(1.8) \\
n=533\end{array}$ \\
\hline CRP > ULN, n (\%) & $\begin{array}{c}137(53.3) \\
n=257\end{array}$ & $\begin{array}{c}159(57.6) \\
n=276\end{array}$ & $\begin{array}{c}296(55.5) \\
n=533\end{array}$ \\
\hline TJC28 & $\begin{array}{c}7.4(6.0) \\
n=257\end{array}$ & $\begin{array}{c}7.9(6.4) \\
n=276\end{array}$ & $\begin{array}{c}7.7(6.2) \\
n=533\end{array}$ \\
\hline SJC28 & $\begin{array}{c}5.5(3.7) \\
n=257\end{array}$ & $\begin{array}{c}5.6(4.1) \\
\mathrm{n}=276\end{array}$ & $\begin{array}{c}5.6(3.9) \\
n=533\end{array}$ \\
\hline Patient's Global Assessment & $\begin{array}{c}6.2(1.9) \\
n=257\end{array}$ & $\begin{array}{c}6.3(1.8) \\
n=276\end{array}$ & $\begin{array}{c}6.3(1.8) \\
n=533\end{array}$ \\
\hline Physician's Global Assessment & $\begin{array}{c}5.8(1.5) \\
n=257\end{array}$ & $\begin{array}{c}5.9(1.6) \\
n=276\end{array}$ & $\begin{array}{c}5.9(1.6) \\
n=533\end{array}$ \\
\hline DAS28(CRP) & $\begin{array}{c}4.6(1.0) \\
n=257\end{array}$ & $\begin{array}{c}4.6(1.0) \\
\mathrm{n}=276\end{array}$ & $\begin{array}{c}4.6(1.0) \\
n=533\end{array}$ \\
\hline DAS28(ESR) & $\begin{array}{c}4.8(1.1) \\
n=224\end{array}$ & $\begin{array}{c}4.9(1.2) \\
n=239\end{array}$ & $\begin{array}{c}4.9(1.1) \\
n=463\end{array}$ \\
\hline CDAl & $\begin{array}{c}24.9(10.2) \\
\mathrm{n}=257\end{array}$ & $\begin{array}{c}25.7(10.8) \\
\mathrm{n}=276\end{array}$ & $\begin{array}{c}25.4(10.5) \\
n=533\end{array}$ \\
\hline SDAI & $\begin{array}{c}26.2(10.5) \\
n=257\end{array}$ & $\begin{array}{c}26.9(11.3) \\
\mathrm{n}=276\end{array}$ & $\begin{array}{c}26.6(10.9) \\
n=533\end{array}$ \\
\hline RAID & $\begin{array}{c}5.7(2.0) \\
n=255\end{array}$ & $\begin{array}{c}5.7(2.0) \\
n=275\end{array}$ & $\begin{array}{c}5.7(2.0) \\
n=530\end{array}$ \\
\hline Pain (RAID-1) & $\begin{array}{c}6.2(2.2) \\
n=255\end{array}$ & $\begin{array}{c}6.1(2.3) \\
n=275\end{array}$ & $\begin{array}{c}6.2(2.2) \\
n=530\end{array}$ \\
\hline SF-12 Physical Component Summary & $\begin{array}{c}32.6(8.5) \\
n=245\end{array}$ & $\begin{array}{c}33.9(8.6) \\
n=262\end{array}$ & $\begin{array}{c}33.3(8.6) \\
n=507\end{array}$ \\
\hline SF-12 Mental Component Summary & $\begin{array}{c}42.4(11.6) \\
\mathrm{n}=245\end{array}$ & $\begin{array}{c}42.6(11.3) \\
n=262\end{array}$ & $\begin{array}{c}42.5(11.5) \\
n=507\end{array}$ \\
\hline HAQ-DI & $\begin{array}{c}1.3(0.7) \\
n=250\end{array}$ & $\begin{array}{c}1.3(0.6) \\
n=270\end{array}$ & $\begin{array}{c}1.3(0.6) \\
n=520\end{array}$ \\
\hline PHQ-9 & $\begin{array}{c}8.9(5.3) \\
n=252\end{array}$ & $\begin{array}{c}8.6(5.3) \\
n=272\end{array}$ & $\begin{array}{c}8.7(5.3) \\
n=524\end{array}$ \\
\hline Erosions, n (\%) & $\begin{array}{c}87(33.9) \\
n=257\end{array}$ & $\begin{array}{c}95(34.4) \\
n=276\end{array}$ & $\begin{array}{c}182(34.1) \\
n=533\end{array}$ \\
\hline
\end{tabular}

Data are mean (SD), $\mathrm{n}$ unless otherwise stated

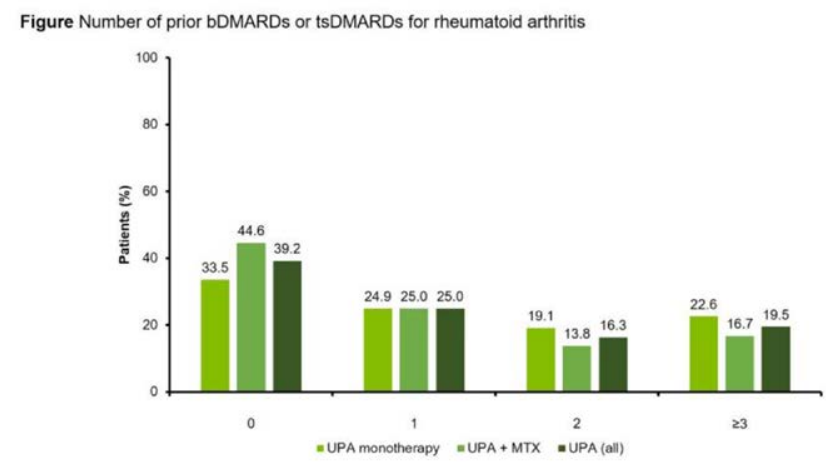

DDMARD, biologic DMARD; DMARD, disease-modifying antirheumatic drug; tsDMARD, targeted synthetic DMARD

Acknowledgements: AbbVie funded this study; contributed to its design; participated in data collection, analysis, and interpretation of the data; and in the writing, review, and approval of the abstract. AbbVie and the authors thank all study investigators for their contributions and the patients who participated in this study. No honoraria or payments were made for authorship. Medical writing support was provided by Grant Thomas Kirkpatrick, MSc, of 2 the Nth (Cheshire, UK), and was funded by AbbVie.

Disclosure of Interests: Torsten Witte Grant/research support from: AbbVie, Amgen, Bristol-Myers Squibb, Celgene, Chugai, Gilead, Janssen, Lilly, MSD, Mylan, Novartis, Pfizer, Roche, and UCB., Uta Kiltz Consultant of: AbbVie, Biocad, Eli Lilly and Company, Grünenthal, Hexal, Janssen, MSD, Novartis, Pfizer, Roche, and UCB, Grant/research support from: AbbVie, Amgen, Biogen, Fresenius, GSK, Hexal, Novartis, and Pfizer, Florian Haas Consultant of: AbbVie, Celgene, Novartis, and Pfizer, Grant/research support from: AbbVie, BMS, Celgene, Chugai, MSD, Novartis, Pfizer, Roche, and Sanofi Genzyme, Elke Riechers Consultant of: AbbVie, Chugai, Novartis, and UCB, Grant/research support from: AbbVie, Chugai, Lilly, Janssen, Novartis, Pfizer, Roche, and UCB, Ulrich Prothmann Grant/research support from: AbbVie, Amgen, Bristol-Myers Squibb, Chugai, Glaxo Smith Kline, Novartis, Pfizer, Roche, Sanofi, SOBI, and UCB, Daniela Adolf Employee of: Employee of StatConsult and may own stock or options, Carsten Holland Employee of: Employee of AbbVie and may own stock or options, Rouven Hecht Employee of: Employee of AbbVie and may own stock or options, Alexander Roessler Employee of: Employee of AbbVie and may own stock or options, Kirsten Famulla Employee of: Employee of AbbVie and may own stock or options, Klaus Krueger Grant/research support from: AbbVie, Biogen, BMS, Celltrion, Gilead, Hexal, Janssen, Lilly, Medac, MSD, Novartis, Pfizer, Roche, and UCB.

DOI: 10.1136/annrheumdis-2021-eular.886

\section{AB0256 BARICITINIB (BARI) VERSUS BIOLOGICS IMPACT ON STEROID TAPERING IN RHEUMATOID ARTHRITIS (RA)}

L. Cometi ${ }^{1}$, C. Bruni ${ }^{1}$, L. Tofani ${ }^{1}$, G. Tesei ${ }^{1,2}$, F. Nacci ${ }^{1}$, G. Fiori ${ }^{1}$, F. Bartoli ${ }^{1}$, M. Matucci-Cerinic ${ }^{1}{ }^{1}$ Careggi University Hospital, Experimental and Clinical Medicine, Division of Rheumatology, Firenze, Italy; ${ }^{2}$ Ospedale "Infermi"di Rimini, Medicina e Reumatologia, Rimini, Italy

Background: Biologic and target synthetic disease modifying anti-rheumatic drugs (bDMARDs and tcDMARDs) are recommended to control RA disease activity, pain and steroid use. Following randomized clinical trials (RCTs) and their post-hoc analyses, the Janus Kinase Inhibitor tsDMARDs BARI was superior to reference bDMARD Adalimumab in reducing disease activity, pain and functional disability. In addition, BARI monotherapy also determined more significant pain reduction and functional improvement when compared to Tocilizumab monotherapy (3).

Objectives: to confirm RCT results in a real-life clinical setting, with focus on disease activity, pain, functional disability and steroid tapering, when comparing BARI to bDMARDs for the treatment of active RA.

Methods: RA patients starting BARI or a bDMARD for active RA were retrospectively evaluated from June 2019 to June 2020. Disease activity (DAS28CRP, SDAI, CDAI), pain visual analogic scale (pain_VAS), functional disability (HAQ) assessments and mean prednisone dosage (pred_dose) were collected at baseline (BL), 3 months (3M) and 6 months (6M) after BARI/bDMARD initiation. The changes of the outcome measures were evaluated between BL-3M, 3M-6M and BL-6M, as well as between BARI and bDMARDs groups. Finally, we assessed the variables associated with prednisone tapering in the whole population.

Results: 90 out of 100 RA patients evaluated (baseline: age $57 \pm 12$ years, disease duration $131 \pm 100$ months, DAS28PCR $4.8 \pm 1.0$, pain_VAS $61 \pm 23 \mathrm{~mm}$ prednisone dose $5.5 \pm 5.3 \mathrm{mg}$ ) were eligible for the study; 49 received BARI and 41 bDMARDs (17 abatacept, 12 TNF inhibitors, 11 tocilizumab, 1 rituximab). At $\mathrm{BL}$, the two groups did not differ statistically in terms of age, sex, disease duration, disease activity, pain_VAS, previous bDMARD failure or ts/bDMARD naive, concomitant conventional synthetic DMARDs treatment, pred_dose. Both BARI and bDMARDs determined a significant reduction in activity scales and $\mathrm{HAQ}$ when comparing BL-3M and BL-6M, with only pain_VAS and pred_dose showing a significant decrease in the $3 \mathrm{M}-6 \mathrm{M}$ interval. When comparing the two groups, BARI showed a significantly higher reduction of pred dose $(-3.2 \pm 5.1$ vs $-1.7 \pm 3.7 \mathrm{mg}$ at $\mathrm{BL}-3 \mathrm{M}$, and $-4.1 \pm 5.3 \mathrm{vs}-1.9 \pm 4.6 \mathrm{mg}$ at $\mathrm{BL}-6 \mathrm{M})$, which was not significant after adjusting for BL pred_dose. No other difference was seen when the two groups, including the numerically higher reduction of pain_VAS in the BARI group $(-29 \pm 28$ vs $-20 \pm 27 \mathrm{~mm}$ at BL- $3 \mathrm{M}$ and $-35 \pm 25$ vs $-30 \pm 28 \mathrm{~mm}$ at BL- $6 \mathrm{M}$ comparison). The analysis of the predictors for steroid tapering ( $\Delta$ mean_pred) in the two intervals, showed that BL DAS28PCR, DAS28PCR BL-3M change and BL pred_dose were associated with BL-3M $\triangle$ mean_pred, while $3 \mathrm{M}$ pain_VAS and $3 \mathrm{M}$ pred_dose were associated with $3 \mathrm{M}-6 \mathrm{M} \Delta$ mean_pred.

Conclusion: Although limited by the small samples and the retrospective nature, our real-life comparison shows similar efficacy of BARI and bDMARDs in terms of disease activity control, functional disability and pain. In addition, the treatment with BARI or bDMARD did not influence the steroid tapering, which was driven mostly by its initial dose, disease activity and pain. Larger real-life multi-center studies are warranted to confirm our results.

\section{REFERENCES:}

[1] Taylor PC et al. Baricitinib versus Placebo or Adalimumab in Rheumatoid Arthritis. N Engl J Med. 2017 Feb 16;376(7):652-662.

[2] Fautrel $\mathrm{B}$ et al. Effect of Baricitinib and Adalimumab in Reducing Pain and Improving Function in Patients with Rheumatoid Arthritis in Low Disease Activity: Exploratory Analyses from RA-BEAM. J Clin Med. 2019 Sep 5;8(9):1394.

[3] Fautrel B et al. Comparative effectiveness of improvement in pain and physical function for baricitinib versus adalimumab, tocilizumab and tofacitinib monotherapies in rheumatoid arthritis patients who are naïve to treatment with

Disclosure of Interests: Laura Cometi: None declared, Cosimo Bruni Speakers bureau: Actelion, Consultant of: Eli Lilly, Grant/research support from: Fondazione Italiana Ricerca sull'Artrite (FIRA), Gruppo Italiano lotta alla Sclerodermia (GILS), New Horizon Fellowship, European Scleroderma Trials and Research (EUSTAR) group, Foundation for Research in Rheumatology (FOREUM)., Lorenzo Tofani: None declared, Giulia Tesei: None declared, Francesca Nacci: None declared, Ginevra Fiori: None declared, Francesca Bartoli: None declared, Marco Matucci-Cerinic Speakers bureau: Biogen 
Italia, Actelion, Bayer, Boehringer Ingelheim, CSL Behring, Eli-Lilly, Consultant of: Biogen Italia, Actelion, Bayer, Boehringer Ingelheim, CSL Behring, EliLilly, Grant/research support from: Biogen Italia, Actelion, Bayer, Boehringer Ingelheim, CSL Behring, Eli-Lilly, DOI: 10.1136/annrheumdis-2021-eular.1343

\section{$\mathrm{AB} 0257$ \\ IMPACT OF CONVENTIONAL ANTIRHEUMATIC TREATMENT ON CARDIOVASCULAR RISK IN PATIENTS WITH RHEUMATOID ARTHRITIS}

D. Gerasimova ${ }^{1}$, E. Gerasimova ${ }^{2}$, T. Popkova ${ }^{2}$, A. Melkumyan ${ }^{1} .{ }^{1}$ I.M. Sechenov First Moscow State Medical University (Sechenov University), Department of Organization and Economy of Pharmacy, Moscow, Russian Federation; ${ }^{2} V . A$. Nasonova Research Institute of Rheumatology, Systemic Rheumatic Diseases Laboratory, Moscow, Russian Federation

Background: Cardiovascular diseases (CVD) are the most common and socially significant comorbidities and the main cause of premature mortality in rheumatoid arthritis (RA). Appropriate RA therapy should not only suppress RA activity, but also reduce CVD risk.

Objectives: To evaluate CVD risk and analyze its association with the use of conventional therapy in RA patients (pts).

Methods: The study included 100 pts with RA (92 women and 8 men) aged 30 to 60 without established CVD. The median age was 49.5 [44.5;53] years, duration of RA was $144[60 ; 240]$ months, DAS28 was 4.4 [3.3;5.3] points. Eighty six RA pts (86\%) treated with disease-modifying antirheumatic drugs (DMARDs) (methotrexate, $n=55$; leflunomide, $n=12$; hydroxychloroquine, $n=8$; sulfasalazine, $n=11$ ), including 33 pts $(33 \%)$ in combination with glucocorticoids (GCs). Fourteen pts (14\%) received monotherapy with GCs. Pts were divided into three treatment groups: DMARDs group, $n=53$; GCs group, $n=14$; DMARDs+GCs group, $n=33$. CVD risk was calculated with ASSIGN, QRISK3, and ERS-RA scales.

Results: No differences were found between the groups when calculating CVD risk using ASSIGN (table 1). Estimated CVD risk by QRISK3 was lower in DMARDs group $(4.9$ [3.0; 7.7]) than in DMARDs+GCs group $(7.1$ [4.1; 13.6], $\mathrm{p}<0.05)$. High CVD risk on the ERS-RA scale was determined less frequently $(13 \%)$ and median CVD risk was lower in DMARDs group (4.2 [2.2; 5.4]) than in GCs group $(57 \% ; 8.9$ [4.8; 11.7], $p<0.01)$ and DMARDs+GCs group (39\%; $6.6[3$; 9.3], p<0.05, respectively). In DMARDs group, significant differences in CVD risk by ERS-RA were found in pts treated with hydroxychloroquine $(2[1.4 ; 5.8])$ and leflunomid $(6.2$ [2.8; 12.3], p<0.05).

Conclusion: RA pts treated with DMARDs have a reduced risk for CVD than pts treated with GCs or a combination of DMARDs and GCs. GCs significantly increase CVD risk. To clarify the impact of hydroxychloroquine and leflunomid on CVD risk, a study on a larger number of pts is required.

Table 1. The impact of conventional antirheumatic therapy on CVD risk.

\begin{tabular}{|c|c|c|c|c|c|c|}
\hline \multirow[t]{2}{*}{ Treatment } & \multicolumn{2}{|c|}{ ASSIGN } & \multicolumn{2}{|c|}{ QRISK3 } & \multicolumn{2}{|c|}{ ERS-RA } \\
\hline & $\begin{array}{c}\text { High } \\
\text { CVD } \\
\text { risk, \% }\end{array}$ & $\begin{array}{c}\text { median } \\
{[25-75} \\
\text { percentiles] }\end{array}$ & $\begin{array}{l}\text { High CVD } \\
\text { risk, \% }\end{array}$ & $\begin{array}{c}\text { median } \\
{[25-75} \\
\text { percentiles] }\end{array}$ & $\begin{array}{l}\text { High } \\
\text { CVD } \\
\text { risk,\% }\end{array}$ & $\begin{array}{c}\text { median } \\
{[25-75} \\
\text { percentiles] }\end{array}$ \\
\hline DMARDs, $n=53$ & 6 & $11[6.5 ; 14]$ & 2 & $4.9[3 ; 7.7]^{\vee}$ & $13^{\star \vee}$ & $4.2[2.2 ; 5.4]$ * \\
\hline GCs, $n=14$ & 7 & $9.5[7 ; 13]$ & 7 & $6.6[4.4 ; 15.8]$ & $57^{*}$ & $8.9[4.8 ; 11.7]$ * \\
\hline $\begin{array}{l}\text { DMARDs+GCs, } \\
n=33\end{array}$ & 15 & $10[5 ; 13.5]$ & 9 & $7.1[4.1 ; 13.6]^{\vee}$ & $39^{v}$ & $6.6[3 ; 9.3]^{v}$ \\
\hline
\end{tabular}

Note: * $-p<0.01$ between pts receiving DMARDs and GCs; ${ }^{\vee}-p<0.05$ between pts receiving DMARDs and DMARDs+GCs.

Disclosure of Interests: None declared

DOI: 10.1136/annrheumdis-2021-eular.1554

\begin{tabular}{|l|l|}
\hline AB0258 & DMARD-TREATMENT OF UNDIFFERENTIATED \\
& ARTHRITIS INTENSIFIED DURING THE LAST \\
& DECENNIA, BUT DID NOT RESULT IN IMPROVED \\
& LONG TERM OUTCOMES
\end{tabular}

M. Verstappen ${ }^{1}$, X. Matthijssen ${ }^{1}$, A. Van der Helm - van Mil ${ }^{1,2} .{ }^{1}$ Leiden University Medical Center, Rheumatology, Leiden, Netherlands; ${ }^{2}$ Erasmus University Medical Center, Rheumatology, Rotterdam, Netherlands

Background: EULAR guidelines stress timely initiation of DMARD-treatment in early arthritis patients also when classification criteria are not yet fulfilled. Consequently, undifferentiated arthritis (UA) patients may be increasingly treated with disease modifying antirheumatic drugs (DMARDs), despite inadequate placebo-controlled evidence for its effectivity. Implementation of this guideline also hampers future placebo-controlled trials in UA. However, historical data, with inclusion period as instrumental variable, can provide insight whether long term outcome is improved with increased DMARD-use, and thus serve to investigate if DMARD-treatment is effective in UA.

Objectives: With 25-years of observational data of newly referred UA-patients we studied whether enhanced treatment strategies resulted in better long term outcomes for UA.

Methods: Between 1993 and 2019, 1132 consecutive UA-patients, not fulfilling the $1987 / 2010$ criteria for RA or any other distinct diagnosis, were included in the Leiden Early Arthritis Cohort; patients were divided in 5 inclusion periods (19931998, 1999-2005, 2006-2010, 2011-2014, 2015-2019). Frequency of DMARD-initiation after diagnosis was compared. We studied the following outcomes: the course of disease activity scores (DAS28-CRP) and Health assessment questionnaires (HAQ), progression to RA after 1-year (according to the 1987 and/or 2010 criteria) and the frequency of prolonged DMARD-free status within 10-years of follow-up (this was defined as either spontaneous remission or sustained remission after discontinuation of DMARD-treatment).

Results: The current population of UA-patients, thus not fulfilling 1987 or 2010 criteria, had rather mild disease: the median SJC was 1, the median TJC 2, 95\% was autoantibody-negative and the median $\mathrm{HAQ}$ was 0.6 . These characteristics were similar in the different inclusion periods. Initiation of DMARD-treatment in UA increased over time: $18 \%, 35 \%, 38 \%, 43 \%$ up to $55 \%$ in respectively 1993 1998, 1999-2005, 2006-2010, 2011-2014 and 2015-2019, in which methotrexate became more common in the last decade. Frequency of progression to RA after 1 -year did not decrease and was $14 \%, 21 \%, 26 \%, 19 \%$ and $28 \%$ in the respective inclusion periods. Long-term DAS28CRP-scores improved from 2011 onwards (range $-0.18,-0.24 ; p<0.05$ ). However HAQ-score over time did no improve compared to the 1993-1998 period (range $-0.00,-0.08 ; p>0.05$ ). Also the percentages of patients in DMARD-free status after 10-years of follow-up did not significantly improve over time: 57\%, 58\%, 59\% (for 1993-1998, 1999-2005, 2006-2010 respectively, $p=0.59$ ).

Conclusion: Intensified DMARD-treatment of patients with UA did not result in improved outcomes. These data may indicate overtreatment of UA-patients. Yet, methods to stratify which UA-patients should be treated remains warranted.

Disclosure of Interests: None declared

DOI: 10.1136/annrheumdis-2021-eular.1559

\section{AB0259 \\ EVALUATION OF THE EFFECT OF FILGOTINIB ON THE PHARMACOKINETICS OF ROSUVASTATIN, ATORVASTATIN, AND PRAVASTATIN}

K. Anderson ${ }^{1}$, C. Nelson ${ }^{1}$, Q. Gong ${ }^{1}$, M. Alani ${ }^{1}$, T. Tarnowski ${ }^{1}$, A. A. Othman ${ }^{1}$.

${ }^{1}$ Gilead Sciences, Inc., Foster City, United States of America

Background: Filgotinib is an orally administered small molecule that preferentially inhibits Janus kinase 1 and is approved for use in Europe and Japan in adult patients with rheumatoid arthritis (RA) who have had an inadequate response to conventional therapies. Patients with RA are at a higher risk of cardiovascular morbidity and mortality relative to the general population ${ }^{1}$. Thus, it is important to understand potential drug-drug interactions of filgotinib with lipid-lowering agents such as statins. Based on in vitro studies, filgotinib is not expected to significantly increase exposure of statins via inhibition of the organic anion transporting peptide (OATP) at clinically relevant exposures. Hence, in Phase 2 and Phase 3 clinical studies, statins were allowed for use with filgotinib. A post-hoc analysis showed no increase in statin-induced AEs such as muscle or liver toxicities when statins were coadministered with filgotinib ("Concomitant Use of Statins in Filgotinib-Treated Patients with Rheumatoid Arthritis: A Post Hoc Analysis", submitted to EULAR 2021)

Objectives: The objectives of this study (NCT04608344) were to evaluate the effect of filgotinib on the pharmacokinetics of atorvastatin, pravastatin, and rosu vastatin, which are sensitive substrates for the OATP-1B1/1B3, and the shortterm safety of administering filgotinib with or without statins.

Methods: This was an open-label, randomized, two-way, crossover study in healthy adult volunteers $(n=27)$. Study participants received a single dose of atorvastatin (ATV $40 \mathrm{mg}$ ) and a single dose of a cocktail of pravastatin (PRA $40 \mathrm{mg}$ )/rosuvastatin (ROS $10 \mathrm{mg}$ ), on two different occasions with washout in between, alone or in combination with filgotinib (200 mg QD for 11 days). Seria pharmacokinetic sampling was performed and pharmacokinetic parameters fo each statin were calculated. Safety was assessed throughout the study. An analysis of variance using a mixed-effects model was applied to the natural logarithmic transformation of pharmacokinetic parameters $\left(C_{\max }\right.$ and $\left.A U C_{i n f}\right)$ for ATV, 2-OH-ATV (active metabolite of ATV), PRA, and ROS. Geometric-least squares means (GLSM) ratios and $90 \%$ confidence intervals $(90 \% \mathrm{Cl})$ of pharmacokinetic parameters were estimated for each analyte and were compared against pre-specified lack of pharmacokinetic alteration boundaries of 70 to $143 \%$.

Results: Of the 27 enrolled participants, 25 participants completed all study treatments. Most AEs and laboratory abnormalities were Grade 1 or 2 in severity; 1 participant discontinued due to a Grade 3 increase in creatine kinase and 1 participant discontinued due to difficulty in blood draws. Following coadminis-

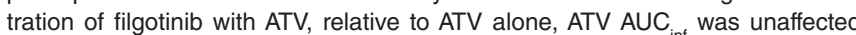

